\title{
CORRESPONDENCE.
}

\section{ON A METHOD OF ADJUSTING TABLES OF MORTALITY.}

To the Editor of the Assurance Magazine.

SiR-It is one of the properties of a table of mortality constructed upon Mr. Gompertz' celebrated formula, that the logarithms of the probability of living one year at successive ages form a series in geometrical progression. These logarithms are necessarily negative; but if their numerical values be denoted by $p_{x}$, then it follows, from the property in question, that log. $p_{x}$ will form a series in arithmetical progression, $i . e$., a series with constant differences of the first order.

Mr. Gompertz' formula, it is well known, cannot be applied, for all ages, to any data which has yet been obtained from actual observation, without first dividing snch data into two or more portions (each comprising a certain number of consecutive ages), and dealing with each portion separately. These several divisions, in fact, form so many independent tables, in each of which the series denoted by $\log . p_{x}$ is in arithmetical progression, but in which the constant differences in the several series are not the same throughout.

The only objection to this mode of proceeding is, that a table so constructed must form a series more or less discontinuous at the points of junction of the several divisions-an objection, however, which may be obviated if we can (without too great a departure from the original data) so modify the several differences that they shall gradually merge into each other, instead of abruptly changing in passing from one division to the following. Now, let $y_{x}$ denote the logarithm of the logarithm of the unadjusted probability of living one year, $-\Sigma y_{x}$ the sum of all the terms from $x$ upwards, then, in the following table-

$$
\begin{aligned}
& \Sigma_{y_{0}} \Delta \Sigma y_{0} \\
& \Sigma_{y_{n}}{ }^{2}{ }^{2} \Sigma y_{0} \\
& { }_{y_{2 n}} \Delta \Sigma y_{n} \Delta^{2} \Sigma y_{n} \\
& \Delta^{3} \Sigma y_{0} \\
& \Sigma y_{3 n}
\end{aligned}
$$

the symbols $\Delta \Sigma y_{0}, \Delta \Sigma y_{n}$, and $\Delta \Sigma y_{2 n}$, will severally denote the sum of $n$ successive terms of $y_{x}$; and if we insert $n-1$ interpolations between each of the terms $\Sigma y_{0}, \Sigma y_{n}$, \&c., using differences as far as the third order, it is clear that we shall have a perfect series consisting of $3 n+1$ terms, the third differences of which are constant throughout. Again: the first order of differences thus obtained is itself a series with constant second differences, and moreover bears this relation to the original series $y_{x}$, viz., that the sum of each consecutive $n$ terms of the former (commencing with the first) is equal to the sum of the corresponding $n$ terms of the latter. We have thus obtained a series, without the slightest discontinuity, which in its general features must more or less resemble the original series $y_{x}$.

The labour required in adjusting a table by this method is not, I think, greater than with the methods commonly used. The arithmetical values of 
the logarithms of the probabilities are of course easily obtained by subtracting the logarithm of the number surviving the year from the logarithm of the number exposed to risk. If the two last-mentioned logarithms be carried to five decimal places, we shall generally have at least three significant figures in the logarithms of the probabilities; and, retaining only that number, the logarithms of these may be rapidly run off by the table for three figures prefixed to Babbage's Logarithms, in which operation it will be sufficient to take out the logarithms to three decimal places only. Again: in interpolating the series $\Sigma y_{x}$, it will be necessary to compute three terms only, as these will suffice to determine the first term of each of the three orders of differences - by the aid of which the remaining terms of the first order of differences (which is the series with which we are concerned) may be obtained by two additions only, as will appear by the following example.

In order to exhibit the results of the method here proposed, and to enable your readers to compare them with the results obtained by a method suggested by one of the latest and ablest writers on the subject, I annex an adjusted table of the Eagle experience, as given in vol. iv., page 214, of The Assurance Magazine. Neglecting the original data for the age of 80 and upwards, as being founded upon numbers too small to render it of any great utility, and dividing the remainder into three parts, the first comprising the ages 20 to 39 , the second, ages 40 to 59 , and the third, the ages 60 to 79 , the preparatory table will stand thus :-

\begin{tabular}{|c|c|c|c|c|}
\hline$x$. & $\Sigma y_{x^{*}}$ & $\Delta \Sigma y_{x^{*}}$ & $\Delta^{2} \Sigma y_{x^{*}}$ & $\Delta^{3} \Sigma y_{x^{*}}$ \\
\hline 20 & 62003 & -13870 & & \\
40 & 48133 & -18962 & -5092 & -5117 \\
60 & 29171 & -29171 & -10209 & \\
80 & 0 & & \\
\hline
\end{tabular}

Interpolating in the ordinary way three terms between the ages 20 and 40, we have :-

\begin{tabular}{|c|c|c|c|c|}
\hline$x$. & $\Sigma y_{x^{*}}$ & $y_{x^{*}}$ & $\Delta y_{x^{*}}$ & $\Delta^{2} y_{x^{*}}$ \\
\hline $\begin{array}{l}20 \\
21 \\
22 \\
23 \\
: \\
:\end{array}$ & $\begin{array}{r}62003 \cdot 0000 \\
61351 \cdot 4413 \\
60699 \cdot 3055 \\
60045-9530 \\
. \quad . \quad . \\
. \quad .\end{array}$ & $\begin{array}{c}-651 \cdot 5587 \\
-652 \cdot 1358 \\
-653.3525 \\
. \quad . \\
. \quad .\end{array}$ & $\begin{array}{r}-5771 \\
-1.2167 \\
. \quad . \\
. \quad .\end{array}$ & $\begin{array}{c}-\cdot 6396 \\
\cdot\end{array}$ \\
\hline
\end{tabular}

Which series, it is evident, may be continued to any extent required, by continually adding the constant second difference, 6396, to the last term of the first order $\Delta y_{x}$, and then adding the several terms of the latter to the corresponding terms of $y_{x^{*}}$ Thus, as before stated, each term of the adjusted series required is obtained by two additions only, it being useless 
to continue the series $\Sigma y_{x}$, which is introduced merely for the purpose of explaining the process.

The next step consists in taking out the numbers corresponding to the logarithms in the column $y_{x}$, by which we obtain the logarithm of the probability of living one year, at all ages, in its negative form, and the logarithms of the numbers living at each age may then be found by the continued subtraction of these from the logarithm of the number fixed for the radix of the table.

The following table contains the numbers living, the decrements, and also the expectation of life, at every age from 20 upwards. By comparing the expectation with that deduced by Mr. Jellicoe's method, it will be found that, upon the whole, the former adheres rather more closely to the original data than the latter. It may also be remarked, that although from the age of 80 upwards the decrements are deduced entirely by a continuation of the law according to which the preceding portion of the table is formed, and are consequently entirely independent of the original observations, yet even at these extreme ages a very close connection is observable between them.

$$
\begin{aligned}
& \text { I am, Sir, } \\
& \text { Your very obedient Servant, }
\end{aligned}
$$

London, 28th November, 1856.

M.

\begin{tabular}{|c|c|c|c|c|c|c|c|c|c|c|c|}
\hline Age. & Living. & $\begin{array}{l}\text { Decre- } \\
\text { ments. }\end{array}$ & $\begin{array}{c}\text { Expecta- } \\
\text { tion of } \\
\text { Life. }\end{array}$ & Age. & Living. & $\begin{array}{l}\text { Decre- } \\
\text { ments. }\end{array}$ & $\begin{array}{c}\text { Expecta- } \\
\text { tion of } \\
\text { Life. }\end{array}$ & Age. & Living. & $\begin{array}{l}\text { Decre- } \\
\text { ments. }\end{array}$ & $\begin{array}{l}\text { Expecta } \\
\text { tion of } \\
\text { Life. }\end{array}$ \\
\hline 20 & $9215 \cdot 0$ & $94 \cdot 6$ & $38 \cdot 447$ & 47 & 6578.9 & $117 \cdot 0$ & $21 \cdot 256$ & 74 & $2230 \cdot 2$ & 194.5 & $6 \cdot 859$ \\
\hline 21 & $9120 \cdot 4$ & $93 \cdot 8$ & $37 \cdot 842$ & 48 & $6461 \cdot 9$ & $119 \cdot 7$ & $20 \cdot 631$ & 75 & $2035 \cdot 7$ & 191.8 & $6 \cdot 466$ \\
\hline 22 & $9026 \cdot 6$ & $93 \cdot 1$ & $37 \cdot 230$ & 49 & $6342 \cdot 2$ & $122 \cdot 5$ & 20.012 & 76 & $1843 \cdot 9$ & $187 \cdot 8$ & 6.087 \\
\hline 23 & $8933 \cdot 5$ & $92 \cdot 5$ & 36.612 & 50 & $6219 \cdot 7$ & 125.5 & $19 \cdot 395$ & 77 & $1656 \cdot 1$ & $182 \cdot 6$ & $5 \cdot 720$ \\
\hline 24 & $8841 \cdot 0$ & $92 \cdot 1$ & 35.991 & 51 & $6094 \cdot 2$ & $128 \cdot 6$ & 18.784 & 78 & 1473.5 & $176 \cdot 0$ & $5 \cdot 367$ \\
\hline 25 & $8748 \cdot 9$ & $91 \cdot 8$ & $35 \cdot 364$ & 52 & $5965 \cdot 6$ & $132 \cdot 0$ & $18 \cdot 179$ & 79 & $1297 \cdot 5$ & $168 \cdot 1$ & $5 \cdot 027$ \\
\hline 26 & $8657 \cdot 1$ & $91 \cdot 6$ & $34 \cdot 734$ & 53 & $5833 \cdot 6$ & $135 \cdot 3$ & $17 \cdot 578$ & 80 & $1129 \cdot 4$ & 158.8 & $4 \cdot 701$ \\
\hline 27 & $8565 \cdot 5$ & $91 \cdot 5$ & $34 \cdot 099$ & 54 & $5698 \cdot 3$ & $138 \cdot 9$ & 16.984 & 81 & $970 \cdot 6$ & $148 \cdot 3$ & 4.388 \\
\hline 28 & $8474 \cdot 0$ & $91 \cdot 6$ & $33 \cdot 462$ & 55 & $5559 \cdot 4$ & $142 \cdot 5$ & $16 \cdot 396$ & 82 & $822 \cdot 3$ & 1365 & $4 \cdot 089$ \\
\hline 29 & $8382 \cdot 4$ & $91 \cdot 9$ & $32 \cdot 822$ & 56 & $5416 . \overline{9}$ & $146 \cdot 3$ & $15 \cdot 814$ & 83 & $685 \cdot 8$ & $123 \cdot 9$ & $3 \cdot 804$ \\
\hline 30 & 8290.5 & $92 \cdot 1$ & $32 \cdot 181$ & 57 & $5270^{\circ} 6$ & 1503 & $15 \cdot 239$ & 84 & 561.9 & 110.5 & 3-532 \\
\hline 31 & $8198 \cdot 4$ & 926 & $31 \cdot 537$ & 58 & $5120 \cdot 3$ & $154^{\circ} 1$ & $14 \cdot 672$ & 85 & $451 \cdot 4$ & $96 \cdot 6$ & $3 \cdot 274$ \\
\hline 32 & 8105.8 & $93 \cdot 2$ & $30 \cdot 891$ & 59 & $4966 \cdot 2$ & $158 \cdot 3$ & $\mid 14 \cdot 112$ & 86 & $354 \cdot 8$ & $82 \cdot 7$ & $3 \cdot 029$ \\
\hline 33 & $8012 \cdot 6$ & $93 \cdot 8$ & $30 \cdot 243$ & 60 & $4807 \cdot 9$ & $162 \cdot 2$ & $13 \cdot 560$ & 87 & $272 \cdot 1$ & $69 \cdot 1$ & $2 \cdot 798$ \\
\hline 34 & 7918.8 & $94 \cdot 6$ & $29 \cdot 597$ & 61 & 46457 & $166^{\circ} 4$ & $13 \cdot 016$ & 88 & $203^{\circ} 0$ & $56 \cdot 1$ & $2: 580$ \\
\hline 35 & $7824 \cdot 2$ & $95 \cdot 6$ & $28 \cdot 948$ & 62 & $4479 \cdot 3$ & $170 \cdot 4$ & 12.481 & 89 & 146.9 & $44 \cdot 2$ & $2: 375$ \\
\hline 36 & $7728 \cdot 6$ & $96 \cdot 7$ & $28 \cdot 301$ & 63 & $4308 \cdot 9$ & $174 \cdot 5$ & 11.955 & 90 & $102 \cdot 7$ & $33 \cdot 7$ & $2 \cdot 183$ \\
\hline 37 & $7631 \cdot 9$ & $97 \cdot 8$ & $27 \cdot 653$ & 64 & $4134^{\circ} 4$ & $178 \cdot 3$ & $11 \cdot 438$ & 91 & $69^{\circ} 0$ & $24 \cdot 6$ & $2 \cdot 003$ \\
\hline 38 & $7534 \cdot 1$ & $99 \cdot 1$ & $27 \cdot 006$ & 65 & $3956^{\circ} 1$ & $182 \cdot 0$ & 10.931 & 92 & $44 \cdot 4$ & $17 \cdot 2$ & $1-836$ \\
\hline 39 & $7435 \cdot 0$ & 1006 & $26 \cdot 358$ & 66 & $3774 \cdot 1$ & 185.4 & $10 \cdot 434$ & 93 & $27 \cdot 2$ & $11 \cdot 4$ & $1 \cdot 680$ \\
\hline 40 & $7334 \cdot 4$ & $102 \cdot 1$ & $25 \cdot 713$ & 67 & $3588 \cdot 7$ & $188 \cdot 6$ & $9 \cdot 947$ & 94 & $15 \cdot 8$ & $7 \cdot 2$ & $1 \cdot 536$ \\
\hline 41 & $7232 \cdot 3$ & $103 \cdot 8$ & 25.068 & 68 & $3400 \cdot 1$ & $191 \cdot 4$ & $9 \cdot 471$ & 95 & $8 \cdot 6$ & $4 \cdot 2$ & $1 \cdot 403$ \\
\hline 42 & $7128 \cdot 5$ & 105.7 & $24 \cdot 426$ & 69 & $3208 \cdot 7$ & 19377 & $9 \cdot 006$ & 96 & $4 \cdot 4$ & $2 \cdot 4$ & 1.281 \\
\hline 43 & 70228 & $107 \cdot 7$ & $23 \cdot 787$ & 70 & $3015 \cdot 0$ & $195 \cdot 5$ & $8 \cdot 553$ & 97 & $2 \cdot 0$ & $1 \cdot 1$ & $1 \cdot 170$ \\
\hline 44 & $6915 \cdot 1$ & $109 \cdot 7$ & $23 \cdot 149$ & 71 & $2819 \cdot 5$ & 196.4 & $8 \cdot 111$ & 98 & $\cdot 9$ & .6 & $1 \cdot 069$ \\
\hline 45 & 6805.4 & $112 \cdot 1$ & $22 \cdot 514$ & 72 & & 19688 & $7 \cdot 681$ & 99 & $\cdot 3$ & 2 & $\cdot 978$ \\
\hline 46 & $6693 \cdot 3$ & 114.4 & $21 \cdot 884$ & 73 & $2426 \cdot 3$ & $196^{\circ} 1$ & $7 \cdot 264$ & 100 & $\cdot 1$ & $\cdot 1$ & .897 \\
\hline
\end{tabular}

Adjusted Mortality Table.-Eagle Experience. 